\title{
Erratum to: Injury Prevention for Modern Dancers: A Pilot Study of an Educational Intervention
}

Tracy L. Fuhrmann • Anne Brayer •

Noelle Andrus $\cdot$ Scott McIntosh

Published online: 13 March 2010

(C) Springer Science+Business Media, LLC 2010

\section{Erratum to: J Community Health}

DOI 10.1007/s10900-010-9223-z

In this article the following company should be listed as follows:

Garth Fagan Dance School

The online version of the original article can be found under doi:10.1007/s10900-010-9223-z.

T. L. Fuhrmann

University of Rochester School of Medicine and Dentistry,

Rochester, NY, USA

\section{A. Brayer}

Department of Emergency Medicine and Pediatrics,

University of Rochester Medical Center, Rochester, NY, USA

N. Andrus

University of Rochester School of Nursing, Rochester, NY, USA

S. McIntosh $(\bowtie)$

Department of Community \& Preventive Medicine,

University of Rochester Medical Center, 120 Corporate Woods,

Suite 350, Rochester, NY 14623, USA

e-mail: scott_mcintosh@urmc.rochester.edu 